\title{
Drinking Water Quality Assessment and Predictive Mapping: Impact of Kota Stone Mining in Ramganjmandi Tehsil, Rajasthan, India
}

\section{Arushi Rana $†$ and Rashmi Sharma}

School of Earth Sciences, Banasthali Vidyapith, Niwai, Tonk, Rajasthan-304 022, India

$†$ Corresponding author: Arushi Rana; aarushi.rana.1992@gmail.com

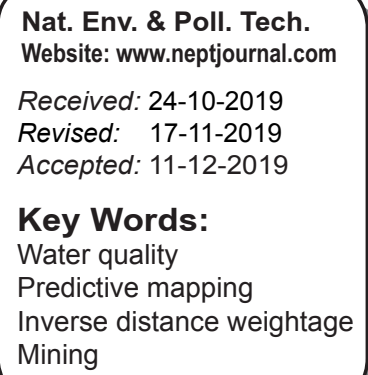

\begin{abstract}
Rajasthan generates 1055 million litres per day as wastewater, out of which 27 million litres is treated and nearly 1028 million litres untreated wastewater is discharged in various water resources. The present study is based on the impact of Kota stone or limestone mining on water resources. Among those villages and census towns, experiencing mining activity, a total of 26 surface water and groundwater samples were tested and analysed. Mining waste often creates eutrophication, toxification, temporary hardness and sometimes permanent hardness. The mining belt was $17.54 \mathrm{~km}^{2}$ in the year 2000 which further increased to $24.25 \mathrm{~km}^{2}$ in the year 2018. The parameters analysed were $\mathrm{pH}, \mathrm{EC}$, TDS, alkalinity, total hardness, calcium and magnesium hardness, DO, COD, chloride, sodium and potassium. The predictive mapping for the mining belt was executed in Arc GIS software using Inverse Distance Weightage (IDW) method. The mean of pH was 9.13 , TDS $457.12 \mathrm{mg} / \mathrm{L}$, total hardness $593.52 \mathrm{mg} / \mathrm{L}$, calcium hardness is $205.54 \mathrm{mg} / \mathrm{L}$, magnesium hardness $387.53 \mathrm{mg} / \mathrm{L}$, COD $442.2 \mathrm{mg} / \mathrm{L}, \mathrm{Na}^{+} 139.9$ $\mathrm{mg} / \mathrm{L}, \mathrm{K}^{+} 19.40 \mathrm{mg} / \mathrm{L}, \mathrm{Cl}^{-} 318.29$, DO $3.04 \mathrm{mg} / \mathrm{L}$ and alkalinity $14.02 \mathrm{mg} / \mathrm{L}$.
\end{abstract}

\section{INTRODUCTION}

Karr (1986) gave five principal factors which comprise the integrity of surface water. The factors are flow and hydrology focussing on land use, velocity, high and low extremes of flow, precipitation, groundwater recharge and discharge. The second factor is habitat and structure focussing on vegetation, siltation, sinuosity, current, instream cover, gradient, channel morphology and bank stability. The third factor is energy source including nutrients, sunlight, seasonal cycles, organic matter and productivity. The fourth factor is biotic parameters including disease predation, competition and parasitism. The last factor is chemical parameters like solubility, adsorption, alkalinity, temperature, dissolved oxygen, $\mathrm{pH}$, turbidity, hardness, organics, nutrients and toxins (Novotny 2003). By 2025 , it is expected that water withdrawals will increase by $50 \%$ in the developed countries and $18 \%$ in developing countries (UNEP 2013). Even if we study the past statistics, the same phenomenon can be seen, in the year 2001 a $\$ 4$ million study of 175 scientists from around the globe sponsored by United Nations summarized few issues such as half of the world's wetlands have been drained destroying their habitats; except for Russia and Canada, all the industrial nations have cleared their natural forests; agricultural land nearly $40 \%$ has been degraded due to erosion, natural depletion and water stress (Novotny 2003). World water development report by the United Nations in the year 2019 states India in the category of the nations facing 25 to $70 \%$ physical water stress. Nearly 780000 deaths occurred due to inadequate water and sanitation services all over the world in the year 2018. The waterborne diseases remain a significant disease burden among vulnerable and disadvantaged group worldwide, especially among low-income economies, $4 \%$ of the population estimated about 25.5 million, suffered from diarrhoea in 2015, among which $60 \%$ were under the age of 5 years (UNESCO 2019).

Hydrochemical analysis is of great significance to the sustainable management of water resource utilization, protection of the ecological environment. Zhang et al. (2019) worked on the surface hydrochemistry of Syr Darya River in Kazakhstan at 39 locations and analysed regional hydrochemical characteristics and evaluated irrigational suitability of the regions. The cations studied were $\mathrm{Na}^{+}, \mathrm{Ca}^{2+}$, and $\mathrm{Mg}^{2+}$ and anions studied were $\mathrm{SO}_{4}{ }^{2-}$ and $\mathrm{Cl}^{-}$. The main hydrochemical type was $\mathrm{Ca}-\mathrm{Mg}-\mathrm{SO}_{4}-\mathrm{Cl}^{-}$.

The $\mathrm{pH}$ value of the study ranges from 7.95 to 9.31 and the mean value of dissolved oxygen is 8.96. the salinity of the surface water varied from $342 \mathrm{mg} / \mathrm{L}$ to $4014 \mathrm{mg} / \mathrm{L} .94 .87 \%$ of samples were above the limit of $500 \mathrm{mg} / \mathrm{L}$ (Zhang et al. 2019). Groundwater aquifers were studied in Regina, Canadian prairies. A total of 14 parameters were selected including eight trace metals: arsenic (As), calcium (Ca), magnesium $(\mathrm{Mg})$, manganese $(\mathrm{Mn})$, potassium $(\mathrm{K})$, sodium $(\mathrm{Na})$, and 
uranium (U), as well as seven anionic species and groundwater parameters: bicarbonate $\left(\mathrm{HCO}_{3}{ }^{-}\right)$, chloride $\left(\mathrm{Cl}^{-}\right)$, sulphate $\left(\mathrm{SO}_{4}{ }^{2-}\right)$, total dissolved solids (TDS), total hardness (TH), $\mathrm{pH}$ and electrical conductivity (EC). A strong correlation is seen between sulphate and calcium, sodium and chloride, and sulphate and magnesium. Calcium and magnesium were also strongly correlated. $63.2 \%$ of the samples fall in the doubtful to unsuitable and unsuitable according to Wilcox Diagram (Pan et al. 2019).

Soleimani et al. (2018) worked the groundwater quality for drinking and irrigational purpose in a rural area of Sarpol-e-Zahab city, Kermanshah province in Iran. Thirty samples were analysed for EC, TDS, TH, $\mathrm{Na}^{+}, \mathrm{Mg}^{2+}, \mathrm{Ca}^{2+}$, $\mathrm{Cl}^{-}$and $\mathrm{SO}_{4}{ }^{2-}$ ionic constituents. Water quality has been assessed according to the United States Department for Agriculture.

Every 2-year monitoring says that the water quality for agriculture lies in the good or excellent category. Spearman's Correlation analysis and factor analysis displays a good correlation between physio-chemical parameters.

The greed to look good, live good and portray good, often leave the natural environment in a dilemma as if it is just for one particular species. Humans are both the polluters and sufferers of environmental damage. It is the relationship between human and environment, which when becomes imbalanced, affects not only humans but also innumerable species existing in the environment. Environmental monitoring helps decision making for both the government and non-governmental organisations.

Ramganjmandi is a tehsil of the district of Kota in the state of Rajasthan, in which lies the Ramganjmandi city (Fig. 1). It is known as a stone city and coriander city. It is $73 \mathrm{~km}$ away towards the south of Kota on the Delhi Mumbai broad gauze railway line. The major minerals mined here are limestone or building stone (52 units), sandstone (2 units), and masonry stone ( 9 units) and stone gravels (Department of Mines and Geology 2014).

The area of Ramganjmandi and the undergoing most important activity of Kota stone and sandstone mining needs specific attention. Monitoring any industrial activity is the first step before finding any solution. The sustainability of any activity should be the key focus before even executing them. The area which is now a dump of a scrap of limestone has not lived in a preferable environment. The heaps of scrap contributing to land degradation; the slurry on soil affecting the soil quality; the continuous grinding; extraction of mineral making the air polluted; the dumpage of waste in the surface water and long term impact on groundwater; health

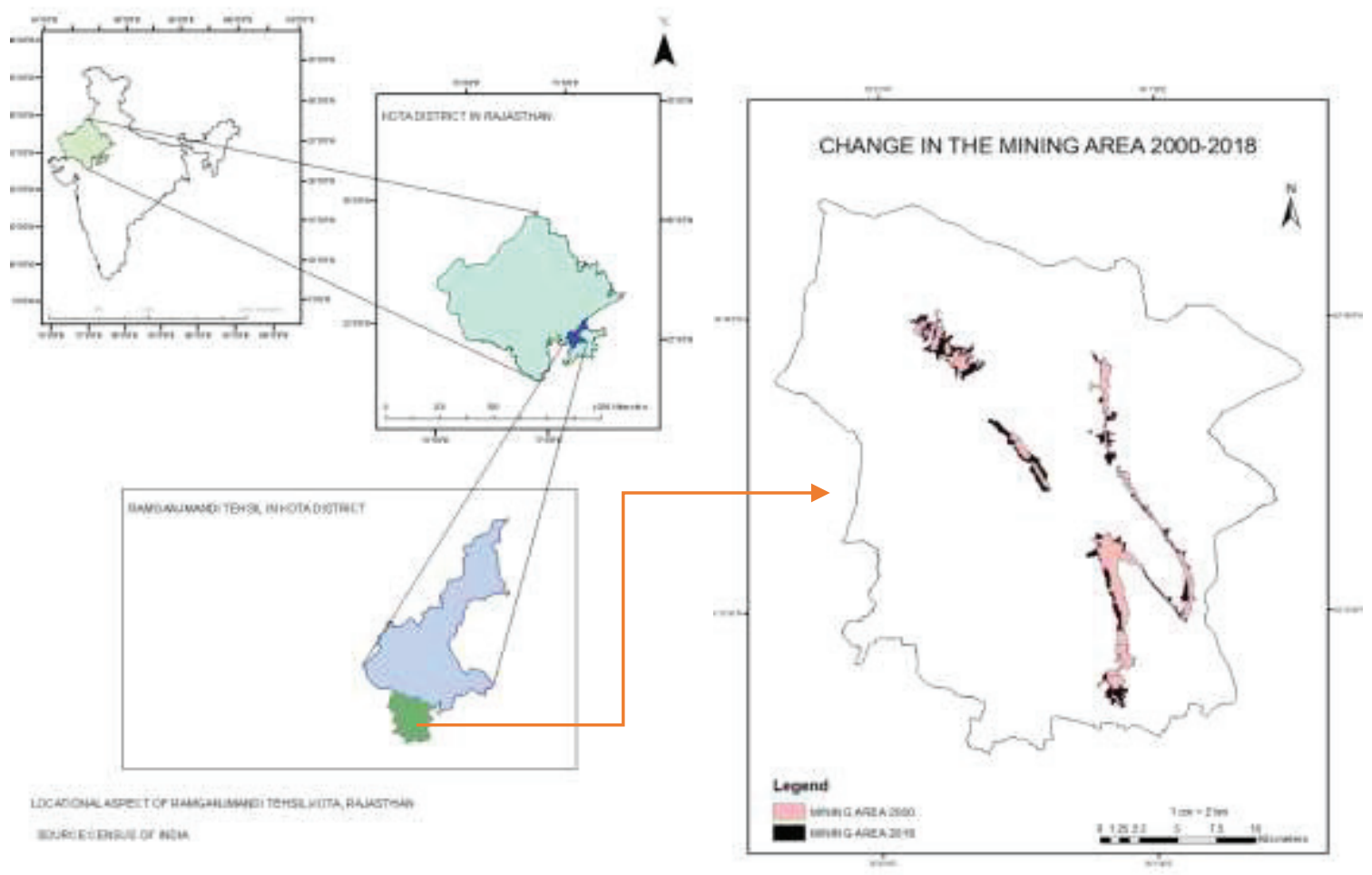

Fig. 1: Location of Ramganjmandi tehsil. 
dilapidation because of the combined effect of ecosystem imbalance are sufficient reasons to make this research problem significant. Ramganjmandi once famous for coriander cultivation is now famous for mines, extraction, poor air quality, water unfit for drinking, loss of agricultural land, deforestation and massive solid waste disposal.

\section{MATERIALS AND METHODS}

\section{Study Area}

The latitudinal extension of Ramganjmandi is $24^{\circ} 08^{\prime} 00^{\prime \prime} \mathrm{N}$ to $24^{\circ} 11^{\prime} 10^{\prime \prime} \mathrm{N}$ and the longitudinal extension is $75^{\circ} 13^{\prime} 04^{\prime \prime}$ E to $76^{\circ} 01^{\prime} 57^{\prime \prime}$ E. Its location is shown in Fig.1. The town is situated on the southwestern portion of Hadoti plateau at an altitude of 357.43 meters above mean sea level. The slope is south to the south-east in direction. The soil is black with some deposits of limestone. The mining belt extended in Kumbhkot, Julmi, Suket, Khemaj, Udupura, Chechat and Kamalpura region. The mining region in the area was 17.548 $\mathrm{km}^{2}$, which now extended to $24.205 \mathrm{~km}^{2}$. The mining area expanded by $6.657 \mathrm{~km}^{2}$.

\section{Water Quality Assessment}

Twenty six water samples (Fig. 2) have been taken from $24.250 \mathrm{~km}^{2}$ area of the mining belt. GPS location was taken along with Juno Trimble. The samples were taken in dark coloured, distilled water-washed bottles. The dissolved oxygen was fixed onsite. $\mathrm{pH}$, electrical conductivity, total dissolved solids and temperature were measured using multi-parameter PC5 TEST R 35 series kit. The sensor was thoroughly washed with distilled water before immersing in the sample. Dissolved oxygen was checked by azide modification Winkler's method. COD was determined with the help of COD reflux apparatus, wherein the wastewater was oxidized completely with potassium dichromate. Alkalinity was estimated by titrating with standard sulphuric acid. Sodium and potassium were determined with the help of flame photometer. Hardness was determined by titrating with standard EDTA reagent. Chloride was measured by Mohr titration method (APHA 1995).

\section{Spatial Interpolation}

Interpolation is the process of predicting unknown values for the non-sampled locations from the known values of sampled locations. Most attempts at spatial predictions are mathematical, based on the geometry and also some attention to the physical nature of the phenomenon (Webster \& Oliver 2007). A static model for water quality has been created for the concerned region with the help of inverse distance weightage method. A shapefile of 26 sampled sites was created as point file in Arc

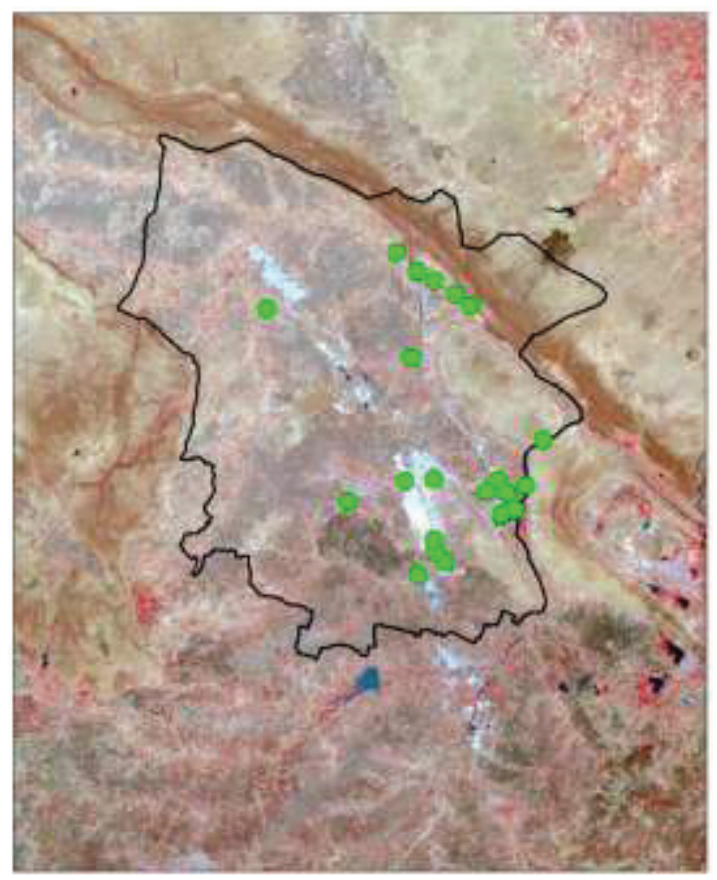

Fig. 2: Sample sites for water collection. 
GIS. The attribute table was created for the 14 parameters. Inverse distance weightage method in Geostatistical Analyst tool was used for interpolation. The details are represented as a raster.

\section{RESULTS AND DISCUSSION}

The water quality with minimum and maximum values is given in Table 1. The correlational matrix as developed according to Karl Pearson's coefficient of correlation shows a high degree of positive correlation (Table 2) between TH-alkalinity ( $\mathrm{r}=0.60)$, magnesium hardness and alkalinity $(\mathrm{r}=0.58)$, chloride-alkalinity $(\mathrm{r}=0.60)$, EC-TDS $(\mathrm{r}=0.88)$, COD-pH ( $\mathrm{r}=0.55)$, TH-chloride (0.99), calcium hardness- $\mathrm{TH}$ $(\mathrm{r}=0.78)$, magnesium hardness-chloride (0.98), magnesium hardness-calcium hardness $(\mathrm{r}=0.75)$ and calcium hardness and chloride ( $\mathrm{r}=0.79)$.

The predictive mapping of water quality parametersinverse distance weightage interpolation is shown in Figs. 3-14.

pH: The region shows $\mathrm{pH}$ values ranging from 6 to 10.9 (Fig. $3)$. Low $\mathrm{pH}$ values are depicted in the southern part of the tehsil in Suket and Kumbhkot regions. The $\mathrm{pH}$ values must range between 6.5 and 8.5 as per BIS standards (Soleimani et al. 2018). Beyond this, the water will affect the mucous membrane and water supply systems. WHO guideline for $\mathrm{pH}$ is 8.5 .

Table 1: Water quality parameters and statistical representation.

\begin{tabular}{|c|c|c|c|c|c|}
\hline Parameters & Minimum & Maximum & St. Deviation & Median & Mean \\
\hline $\mathrm{EC}(\mu \mathrm{S})$ & 367 & 939 & 140.1 & 692.3 & 675.29 \\
\hline TDS (mg/L) & 261 & 666 & 87.212 & 450 & 457.12 \\
\hline Temperature $\left({ }^{\circ} \mathrm{C}\right)$ & 29 & 33.4 & 1.085 & 31.2 & 31.04 \\
\hline Total hardness (mg/L) & 128 & 2740 & 755.46 & 275 & 593.52 \\
\hline Calcium hardness (mg/L) & 58.8 & 588 & 148.54 & 187.5 & 205.54 \\
\hline Magnesium hardness (mg/L) & 56 & 2183.5 & 619.23 & 143.6 & 387.53 \\
\hline $\mathrm{COD}(\mathrm{mg} / \mathrm{L})$ & 96 & 698 & 201.76 & 450 & 442.2 \\
\hline $\mathrm{DO}(\mathrm{mg} / \mathrm{L})$ & 1.8 & 5.8 & 0.865 & 3.7 & 3.04 \\
\hline $\mathrm{Na}(\mathrm{mg} / \mathrm{L})$ & 32.6 & 570 & 165.11 & 61 & 139.9 \\
\hline $\mathrm{K}(\mathrm{mg} / \mathrm{L})$ & 1.18 & 86.3 & 27.769 & 5.1 & 19.403 \\
\hline Chloride (mg/L) & 57 & 1593.2 & 447.16 & 110 & 318.29 \\
\hline Alkalinity (mg/L) & 8 & 20 & 3.35 & 14 & 14.02 \\
\hline
\end{tabular}

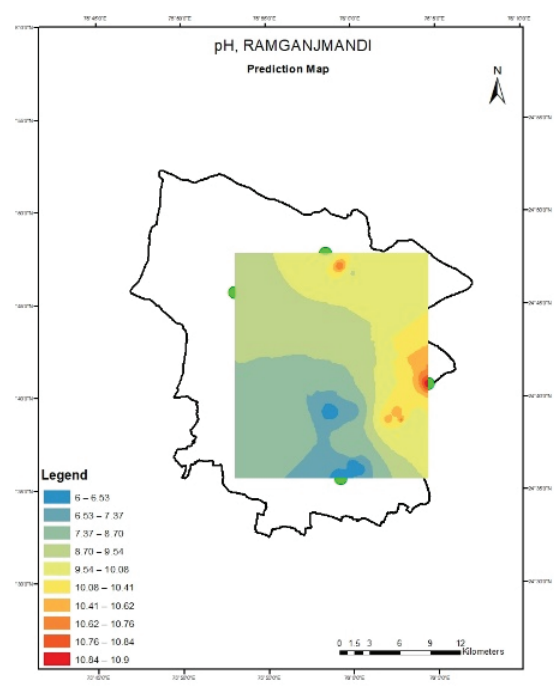

Fig. 3: $\mathrm{pH}$

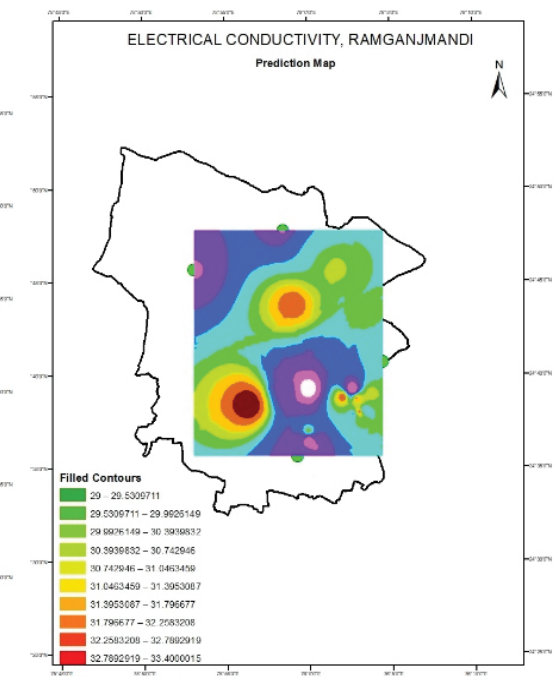

Fig. 4: Electrical Conductivity

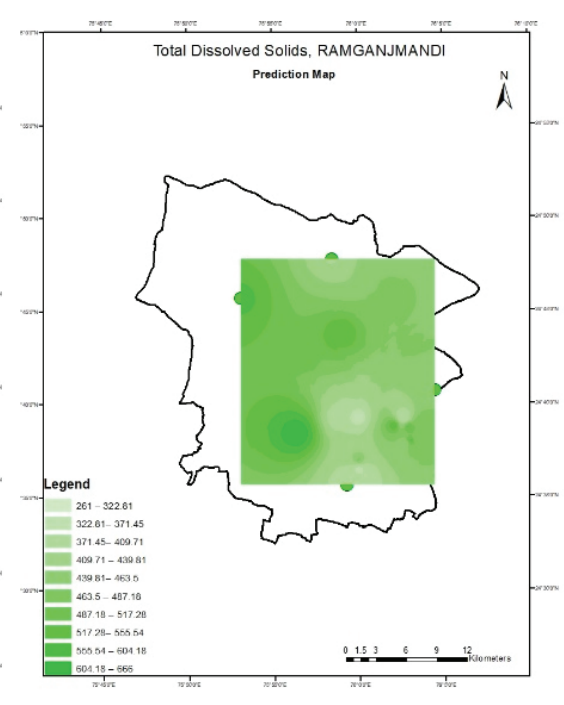

Fig. 5: Total disslved solids 
Table 2: Correlational matrix of water quality parameters.

\begin{tabular}{|c|c|c|c|c|c|c|c|c|c|c|c|}
\hline & Temp & $\mathrm{pH}$ & TDS & Alkalinity & $\mathrm{TH}$ & Mg hardness & Chloride & COD & $\mathrm{EC}$ & Ca hardness & DO \\
\hline Temperature & 1 & & & & & & & & & & \\
\hline $\mathrm{pH}$ & 0.49 & 1.00 & & & & & & & & & \\
\hline TDS & 0.18 & 0.33 & 1.00 & & & & & & & & \\
\hline Alkalinity & -0.32 & -0.50 & -0.41 & 1.00 & & & & & & & \\
\hline $\mathrm{TH}$ & -0.44 & -0.84 & -0.46 & 0.60 & 1 & & & & & & \\
\hline Mg Hardness & -0.44 & -0.82 & -0.48 & 0.58 & 1.00 & 1 & & & & & \\
\hline Chloride & -0.48 & -0.87 & -0.48 & 0.60 & 0.99 & 0.98 & 1 & & & & \\
\hline COD & 0.20 & 0.55 & 0.29 & -0.20 & -0.44 & -0.44 & -0.48 & 1 & & & \\
\hline $\mathrm{EC}$ & 0.24 & 0.35 & 0.88 & -0.22 & -0.43 & -0.46 & -0.45 & 0.44 & 1 & & \\
\hline Ca Hardness & -0.25 & -0.71 & -0.19 & 0.51 & 0.78 & 0.75 & 0.79 & -0.32 & -0.05 & 1 & \\
\hline DO & 0.35 & 0.43 & -0.12 & -0.08 & -0.24 & -0.21 & -0.30 & -0.05 & -0.18 & -0.37 & 1 \\
\hline
\end{tabular}

Electrical conductivity: The values of EC range from 367 to $939 \mu \mathrm{S}$ (Fig. 4). The mean value is $675.29 \mu \mathrm{S}$ and standard variation is $140.1 \mu \mathrm{S}$ depicting a high variability (Table 1 ). Most of the samples lie in the excellent, good and permissible category of agricultural suitability (Richards 1954). Wherein, $79.8 \%$ of samples lie in the permissible category and rest lie under the good and excellent category.

Total dissolved solids: The values of TDS vary from 261 to $666 \mathrm{mg} / \mathrm{L}$ (Fig. 5). High TDS concentration lies in the southeastern region. The TDS values above $500 \mathrm{mg} / \mathrm{L}$ are unacceptable according to BIS standards, beyond this the palatability decreases and water may cause gastrointestinal irritation. $25 \%$ of the samples lie under the unsuitable category of drinking water. The mean value is $457.12 \mathrm{mg} / \mathrm{L}$ (Table
1). WHO reports on TDS and health in areas surveyed like Australia and the Soviet Union indicate that the high TDS causes inflammation of gallbladder and stones increased over a period of 5 years. High TDS level often results in scaling of water pipes, water heaters, boilers, household equipment like kettles as it increases the corrosive ability of the water.

COD: Chemical Oxygen demand is the amount of oxygen required for oxidation of most organic matter and oxidizable inorganic substances with the help of a strong chemical oxidant. The higher the COD, more is the water organically polluted. The COD content for the region varies from 96 to $698 \mathrm{mg} / \mathrm{L}$. The mean value of COD is $442.2 \mathrm{mg} / \mathrm{L}$ (Table 1). The IDW interpolated sites show water with a high value of COD in the southeastern section, wherein River Aru flows

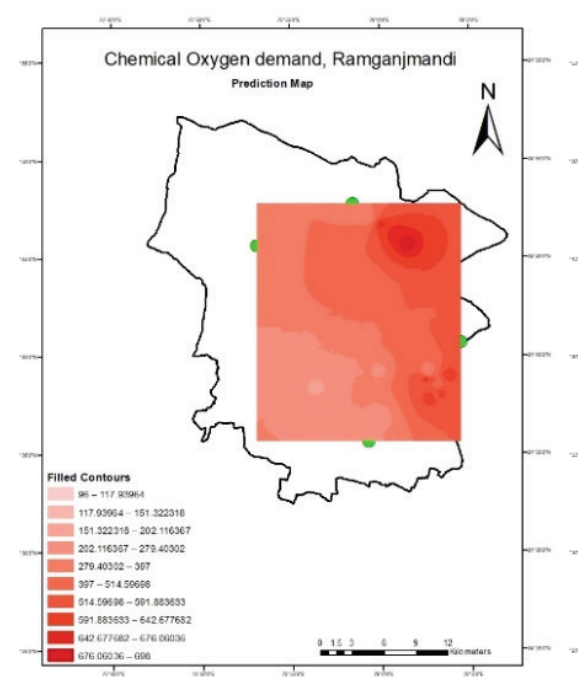

Fig. 6: Chemical Oxygen Demand

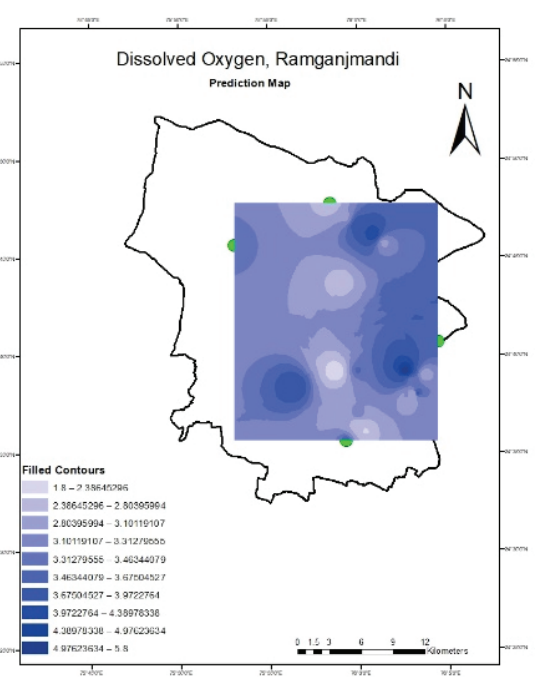

Fig. 7: Dissolved Oxygen

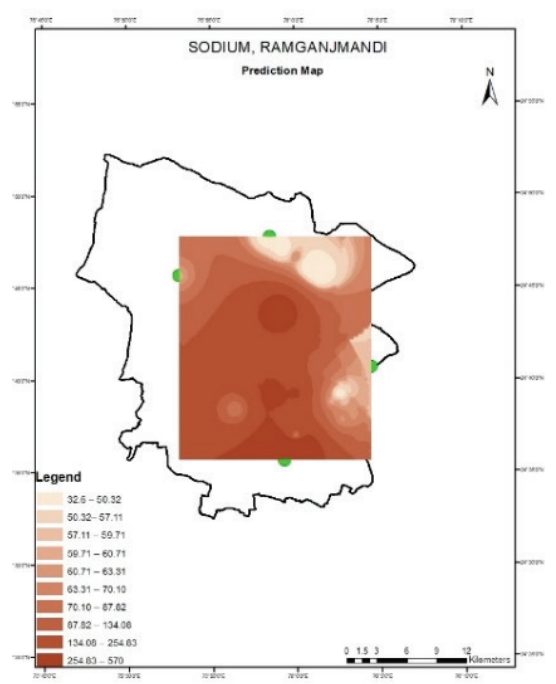

Fig. 8: Sodium 
on the boundary of the Tehsil between Kota and Jhalawar districts of Rajasthan (Fig. 6). The river shows high COD content which is indicative of dumpage of inorganic waste from the mining industry.

Dissolved oxygen: The dissolved oxygen in the region varies from 1.8 to $5.8 \mathrm{mg} / \mathrm{L}$ and the mean value is $3.04 \mathrm{mg} / \mathrm{L}$ (Table 1). The standard deviation of DO is 0.865 showing less variability. For class A streams, $6 \mathrm{mg} / \mathrm{L}$ is required (CPCB 1979). A level of $5-8 \mathrm{mg} / \mathrm{L}$ is suitable for healthy fish growth. The DO concentration is minimum in the pre-monsoon period due to high temperature (Fig. 7).

Sodium: Sodium is ubiquitous in water. A taste threshold value of 30 to $60 \mathrm{mg} / \mathrm{L}$ is accepted by US EPA. BIS standards state $200 \mathrm{mg} / \mathrm{L}$ as sodium concentration limit. The sodium concentration in the Tehsil has a maximum value of 570 $\mathrm{mg} / \mathrm{L}$ in the southern part and the minimum value of $36 \mathrm{mg} / \mathrm{L}$ (Table 1). The standard deviation is high as 165.11 , showing a higher degree of variability in the sampled sites (Fig. 8). The river water shows appropriate sodium concentration throughout its flow. High $\mathrm{Na}$ in the water in the form of chloride and sulphate makes the water unfit for consumption. High Na concentration also leads to hypertension (Maiti 2011). Increased intake of sodium content is detrimental to people suffering from hypertension, heart diseases and kidney problems (Kundu \& Nag 2018).

Potassium: The potassium concentration varies from 1.18 to $86.3 \mathrm{mg} / \mathrm{L}$. The sampled sites show a higher degree of variability with a standard deviation of 27.76 (Table 1 ). The mean value is $19.40 \mathrm{mg} / \mathrm{L}$ (Fig. 9). The southern part shows a higher potassium concentration.
Total hardness: The water of the region turns out to be hard(Fig. 10). The values range from 140 to $2740 \mathrm{mg} / \mathrm{L}$ (Table 1). BIS standards for $\mathrm{TH}$ is $200 \mathrm{mg} / \mathrm{L}$ and relaxation is till $600 \mathrm{mg} / \mathrm{L}$ in case of absence of an alternative source. Low hardness is seen in the upper course of the River Aru wherein it flows through the reserved forest. $92.3 \%$ of the samples are unfit for drinking as per BIS standards. Since the region has limestone-based geology, the hardness increases in such cases. All the samples lie in the hard to very hard category.

Calcium hardness: The calcium concentration should be 75 $\mathrm{mg} / \mathrm{L}$ or may extend to $200 \mathrm{mg} / \mathrm{L}$ in case of absence of an alternative source. The calcium hardness in the region varies from 58.8 to $588 \mathrm{mg} / \mathrm{L}$ (Table 1). $92.3 \%$ of the samples are unfit for drinking purpose.

Magnesium hardness: The required limit for magnesium hardness is $30 \mathrm{mg} / \mathrm{L}$ and the tolerance limit is $100 \mathrm{mg} / \mathrm{L}$. The region has a maximum of $2183.5 \mathrm{mg} / \mathrm{L}$ and a minimum of $56 \mathrm{mg} / \mathrm{L}$ (Table 1). The region shows high variability in the magnesium hardness. The southern part shows a higher magnesium concentration (Fig. 12).

Alkalinity: It is measured as the buffering capacity of bases to neutralize acids. It depicts the capability of water to resist change in $\mathrm{pH}$. The alkalinity in the region varies from 8 to 20 $\mathrm{mg} / \mathrm{L}$ (Fig. 13). Alkalinity in itself is not harmful to human beings but water supply with less than $100 \mathrm{mg} / \mathrm{L}$ is desirable. At higher levels, alkalinity imparts a bitter taste to the water.

Chloride: The chloride level should be less than $200 \mathrm{mg} / \mathrm{L}$ as per WHO standards. $30.76 \%$ of the sampled sites exceed this criterion. The maximum value of chloride is 1593.24 $\mathrm{mg} / \mathrm{L}$ and the minimum value is $57 \mathrm{mg} / \mathrm{L}$ (Fig. 14).

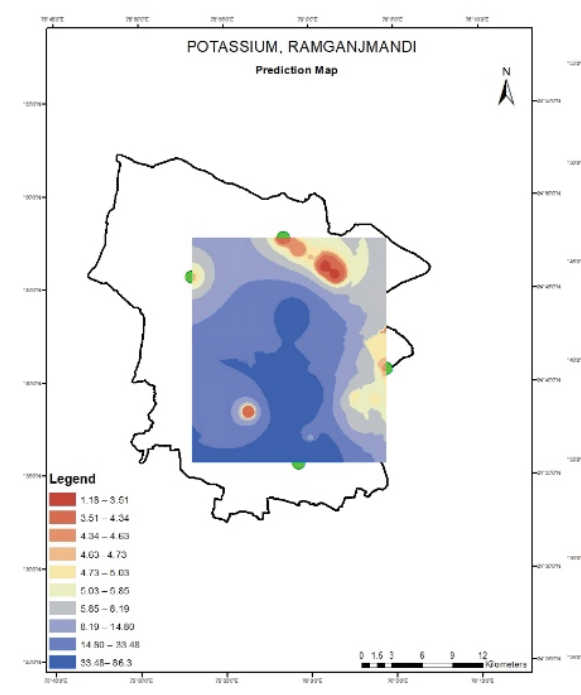

Fig. 9: Potassium

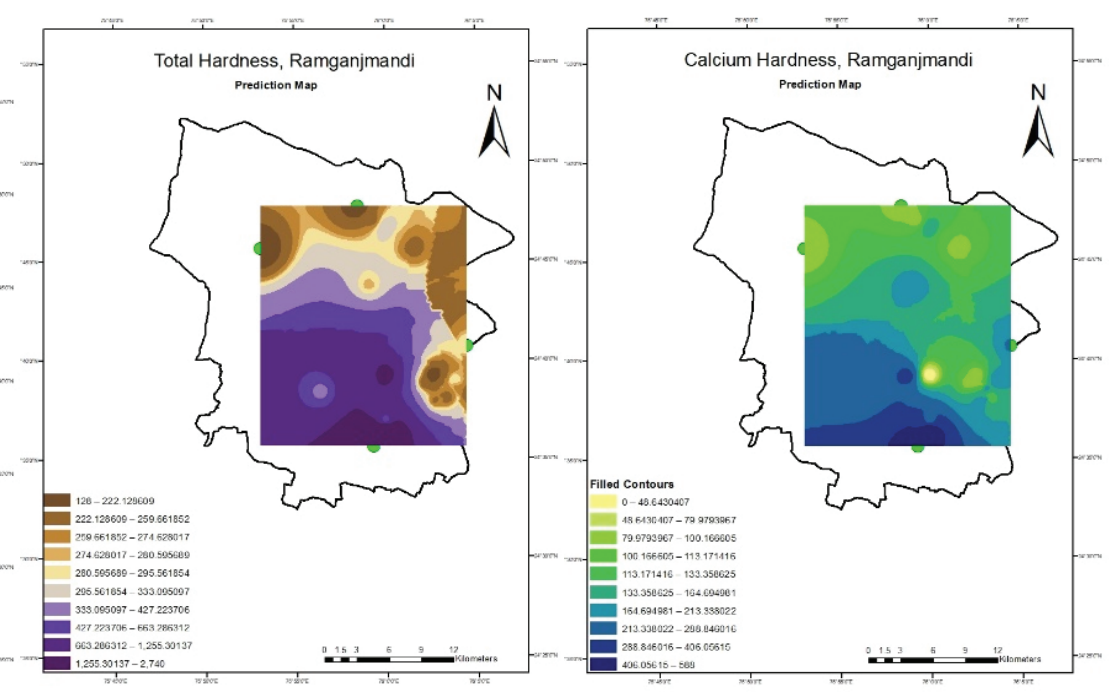

Fig. 10: Total Hardness
Fig. 11: Calcium Hardness 


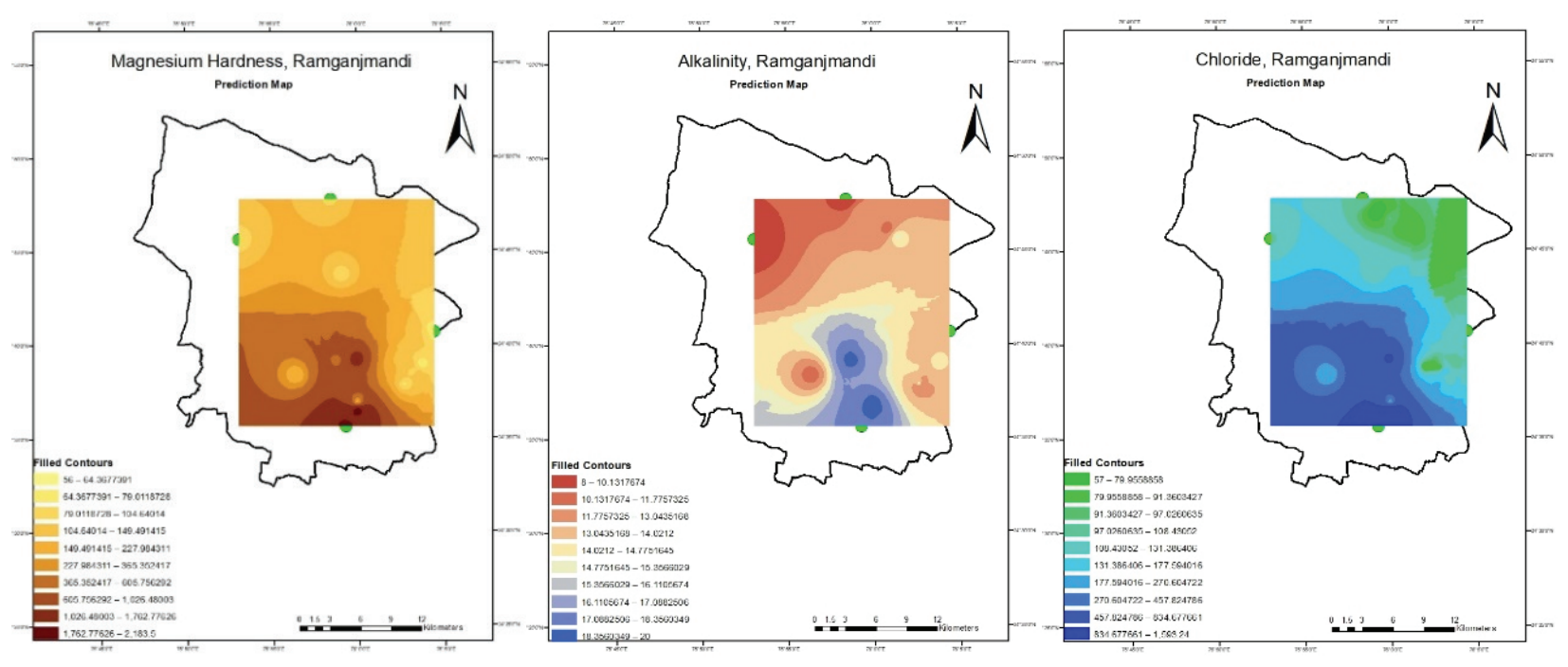

Fig. 12: Magesium Hardness

Fig. 13: Alkalinity

Fig: 14: Chloride

\section{CONCLUSION}

The study depicts a high degree of correlation between the TH-alkalinity, magnesium-alkalinity, chloride-alkalinity, ECTDS, COD-pH, TH-chloride, calcium-TH, magnesium-chloride, magnesium-calcium and calcium-chloride. Such type of correlation can be attributed to limestone-based geology in case of groundwater and limestone mining in case of surface water. The alkalinity levels in the region seem to be under control. The chloride level is considerably high in the Kumbhkot region. In terms of hardness, most of the samples are unfit for drinking purpose. The level of dissolved oxygen is adequate among all the samples. Water seems to be alkaline as per the $\mathrm{pH}$ values of the samples. Sodium and potassium levels are under the prescribed limit, but in the southern part of the tehsil, it is as high as $560 \mathrm{mg} / \mathrm{L}$. High COD levels are seen in the water samples of Aru river, indicating mining waste disposal in the river.

\section{ACKNOWLEDGEMENT}

The authors sincerely acknowledge the support of the Institution, Banasthali Vidyapith Rajasthan, for providing a research-friendly environment and infrastructural facility.

\section{REFERENCES}

APHA 1995. Standard Methods For The Examination of Water and Wastewater. American Public Health Association, Washington DC.

CPCB 1979. Surface Water Quality Criteria for Different Uses. Central Pollution Control Board, New Delhi.
Department of Mines and Geology 2014. Minor minerals, production, income and number of labours. Ramganjmandi, Kota, Rajasthan.

Karr, J.R. 1986. Assessing Biological integrity in running waters a method and its rationale. Special Publication/Illinois Natural History Survey, USA, 5: 2-22.

Kundu, A. and Nag, S.K. 2018. Assessment of ground water quality in Kashipur block, Purulia District, West Bengal. Applied Water Sciences, 40(1): 33-51.

Maiti, S.K. 2011. Handbook of Methods in Environmental Studies: Air, Noise, Soil and Overburden Analysis. Oxford Book Company, Jaipur.

Novotny, V. 2003. Water Quality: Diffuse Pollution and Watershed Management. John Wiley \& Sons, New Jersey.

Oliver, M.A. and Webster, R. 2007. Geostatistics For Environmental Scientists. John Wiley \& Sons, West Sussex, England.

Pan, C., Ng, K.T.W. and Richter, A. 2019. An integrated multivariate statistical approach for the evaluation of spatial variations in groundwater quality near an unlined landfill. Environmental Science and Pollution Research, 26(6): 5724-5737.

Richards, L. 1954. Diagnosis and Improvement of Saline and Alkali Soils. Agriculture Handbook. United States Salinity Laboratory, USDA, Washington.

Soleimani, H., Abbasnia, A., Yousefi, M., Mohammadi, A.A. and Khorasgani, F.C. 2018. Data on assessment of groundwater quality for drinking and irrigation in rural area Sarpol-E Zahab City, Kermanshah Province Iran. Data in Brief,17(1): 148-156. doi:10.1016/j. dib.2017.12.061

UNEP 2013. A Snapshot on World Water Quality Towards A Global Assessment. Nairobi, Kenya.

UNESCO 2019. United Nations World Water Development Report Leaving No One Behind. Paris, France.

Webster, R. and Oliver, M.A. 2007. Geostatistics for Environmental Scientists. John Wiley \& Sons.

Zhang, W., Ma, L., Abuduwaili, J., Ge, Y., Issanova, G. and Saparov, G. 2019. Hydrochemical Characteristics and irrigational suitability of surface water in the Syr Darya river Kazakhstan. Environ. Monit. Assess.,191(9): 572. 